\title{
Chapter 4 \\ Production of Ceramic Steel Composite Castings Through Infiltration
}

\author{
Paul Rähmer, Claudia Dommaschk and Gotthard Wolf
}

\begin{abstract}
TRIP-matrix composites unite the outstanding properties of austeniticmartensitic cast steels with those of ceramics. To manufacture them via infiltration by steel melt, basic investigations are needed. Therefore, the following aspects were studied: the influence of sodium silicate bonded sand molds on solidification of high alloyed TRIP-steels, chemical reactions between steel and molding sand and the positive impact of sulfur and phosphorus on the infiltration quality. Composite materials made of steel and ceramics, in particular, melt-broken zircon corundum, have comparatively high wear resistance. The wear behavior of the composites is characterized by a ring-block test rig. In order to generate a stable bond between the steel and the ceramic phase, the ceramics were coated with titanium oxide prior to infiltration. During infiltration of the coated ceramics, spinel compounds are formed which reduce expansion-related cracks in the boundary layer.
\end{abstract}

\subsection{Introduction}

A combination of different materials enables a targeted combination of material advantages while reducing lagging. Composite materials made of metals and oxides show high innovative potential .

The materials produced primarily by powder metallurgical (PM) processes offer a wide range of applications. Due to the high manufacturing costs of PM processes however, the production of composite materials using suitable casting processes is an important alternative. A combination of the properties of newly developed TRIP/TWIP alloys, which have a high deformation potential and also a high energy

\footnotetext{
P. Rähmer

Albert Hoffmann GmbH, Bergrather Straße 66-70, 52249, Eschweiler, Germany

e-mail: p.raehmer@albert-hoffmann.de

C. Dommaschk $(\bowtie) \cdot$ G. Wolf

Foundry Institute, Technische Universität Bergakademie Freiberg, Bernhard-von-Cotta-Str. 4, 09599, Freiberg, Germany

e-mail: Claudia.Dommaschk@gi.tu-freiberg.de 
absorption capacity, with a wear-resistant ceramic enables the production of fractureresistant, wear-resistant components [1].

For the production of the MMCs basic investigations are necessary and different ways for the production of these are pointed out.

\subsection{Thermal and Chemical Interactions Between Casted High Alloyed TRIP-Steel and Molding Systems}

For the infiltration of macro porous $\mathrm{ZrO}_{2}$ ceramic filter by liquid TRIP-steel melt a special mold, shown in Fig. 4.1, was developed [2, 3]. The depicted mold consists of an infiltration area in the middle of the mold with a height of $100 \mathrm{~mm}$ and a diameter of $50 \mathrm{~mm}$. Floating of the ceramics foams into the feeder is prevented by quartz rods and a filter located underneath. The feeder is equipped with an outlet to ensure uniform metallostatic pressure and the bottom outlet allows more melt to flow through the infiltration area. The solidification time has a high impact on the infiltration quality of the TRIP-matrix materials and is influenced particularly by the molding material. Therefore, the solidification times of three different types of molding sands were investigated. In addition, the modification of the steel composition near the molding material was discussed. As molding sand for the ester hardened sodium silicate bounded mold, H32 (silica sand), chromite sand and Cerabeads 650 (synthetic mullite) were used. Because of the high density, the chromite sand has a binder content of only 2 mass $\%$, while the other molding sands are bound with 3.5 mass $\%$ binder. The temperature was measured in the middle of the infiltration area by $\mathrm{Pt}-\mathrm{Rh} / \mathrm{Pt}$ thermocouples $[2,3]$.

Fig. 4.1 Top pouring infiltration mold with floating preventing ceramic foams and quartz rods

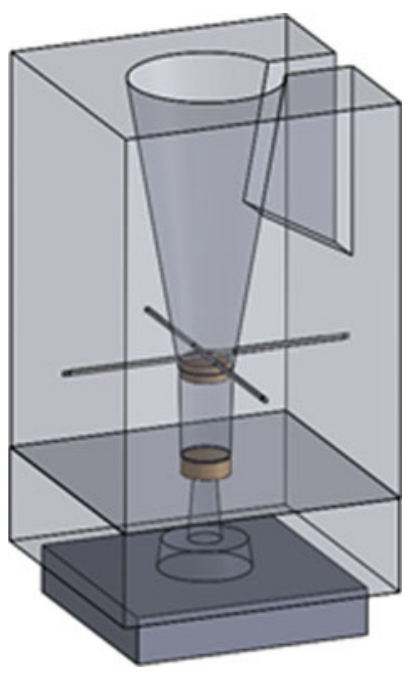




\subsubsection{Solidification Time Depending on the Molding Sand}

The different molding sands have a strong effect on the cooling of the casting, and thus also on the solidification time of the steel. As shown in Fig. 4.2 the castings solidify faster in molds containing chromite sand than silica sand or Cerabeads. These results can be used to achieve a maximum solidification time, and thus to give the infiltration of the ceramics as much time as possible. Furthermore, the solidification can be specifically controlled by the use of the various molding sands, so that feeders or chills could be saved.

The different cooling times can mainly be explained by the different thermal conductivities and specific heat capacity. The thermal conductivity of Cerabeads is the lowest. Up to a temperature of $625^{\circ} \mathrm{C}$, chromite sand has a higher thermal conductivity and higher specific heat than silica sand, hence the amount of heat dissipated in this range is significantly greater and the castings tend to solidify faster $[2,4]$.

With the choice of molding sands the solidification time of the TRIP steel can be controlled and modified. Chromite sand has a cooling effect, while Cerabeads are insulating and therefore, they are best suited for the infiltration process [2, 3].

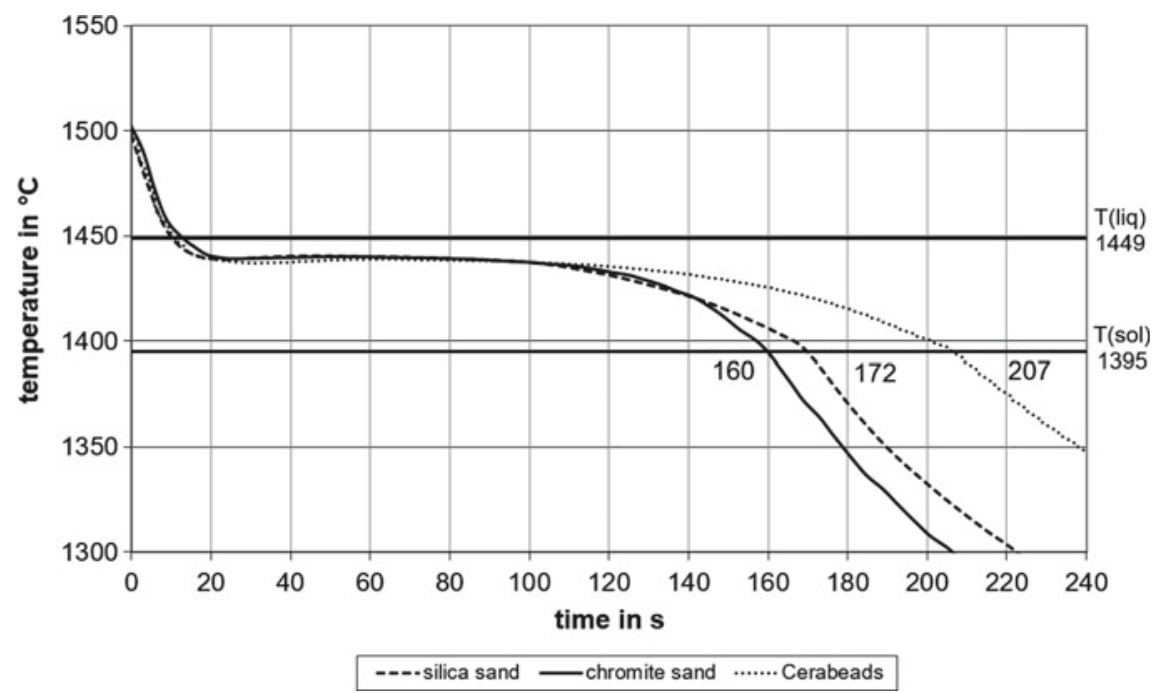

Fig. 4.2 Cooling curves of cast $\mathrm{X} 3 \mathrm{CrMnNi}$ 16-7-6 TRIP-steel cylinders containing liquidus and solidus temperature depending on molding systems. Adapted from Weider [3] 


\subsubsection{Chemical Interactions Between Steel and Mold}

The composition of the used steel is given in Table 4.1. To investigate the chemical interactions, samples were taken from the different thermally loaded layers of the molding material and were wet-chemically analyzed. The results are shown in Table 4.2. In addition, the bound and unbound molding materials were also examined without thermal loading. Locally, the exchange of elements is mainly restricted to the sintering zone, which is in direct contact with the melt. The organic components contained in the binder, e.g. the ester, are responsible for an increase of the carbon content in the melt. The chemical interactions can be measured in the molding sand and the casted steel. The exchange of the elements depends on the composition of the molding sand and their thermal behavior. Particularly noteworthy is the reactive element manganese through the combination of high vapor pressure and oxygen affinity [5]. This results in a strong degradation of acid refractory materials, so that especially the silica sand reacts with the manganese of the melt.

It can be concluded that all basic mold materials tend to accumulate alloying elements in the sintered layer. Cerabeads appear to form a very dense sintered layer, as there were found low levels of chromium and iron. Silica sand is relatively strongly enriched with $\mathrm{MnO}$ in the sintered layer, which only influences the casting composition locally at the surface [2].

\subsection{Influence of the Ceramic Preheating Temperature and Phosphorus as Alloying Element on the Infiltration Quality}

To determine the influence of the preheating temperature and the porosity of the ceramics, the top pouring infiltration was arranged according to the test described above. The casting temperature of the inductive melted steel, according to Table 4.1, was constant at $1600{ }^{\circ} \mathrm{C}$. The ceramic preforms consisting of piled filters were preheated in an electric furnace to temperatures around $200,600,1000$ and $1400{ }^{\circ} \mathrm{C}$. To study the basic effects with molten steel and the general mechanism of the infiltration process commercial pouring filters where used, manufactured by Drache $\mathrm{GmbH}$, Germany, with a porosity of $10 \mathrm{ppi}$. The quantification of the infiltration quality was done by measuring the infiltratable cavity thickness inside of the ceramics and by relating the infiltrated fraction of these cavities to the investigated area of the casting.

Table 4.1 Chemical composition of the used high-alloyed steel in mass\% [3]

\begin{tabular}{l|l|l|l|l|l|l}
\hline & $\mathrm{C}$ & $\mathrm{Si}$ & $\mathrm{Mn}$ & $\mathrm{Cr}$ & $\mathrm{Ni}$ & $\mathrm{Fe}$ \\
\hline X3CrMnNi 16-7-3 & 0.035 & 0.89 & 7.21 & 16.36 & 3.09 & Bal. \\
\hline X3CrMnNi 16-7-6 & 0.05 & 1.06 & 7.10 & 16.20 & 5.94 & Bal. \\
\hline
\end{tabular}




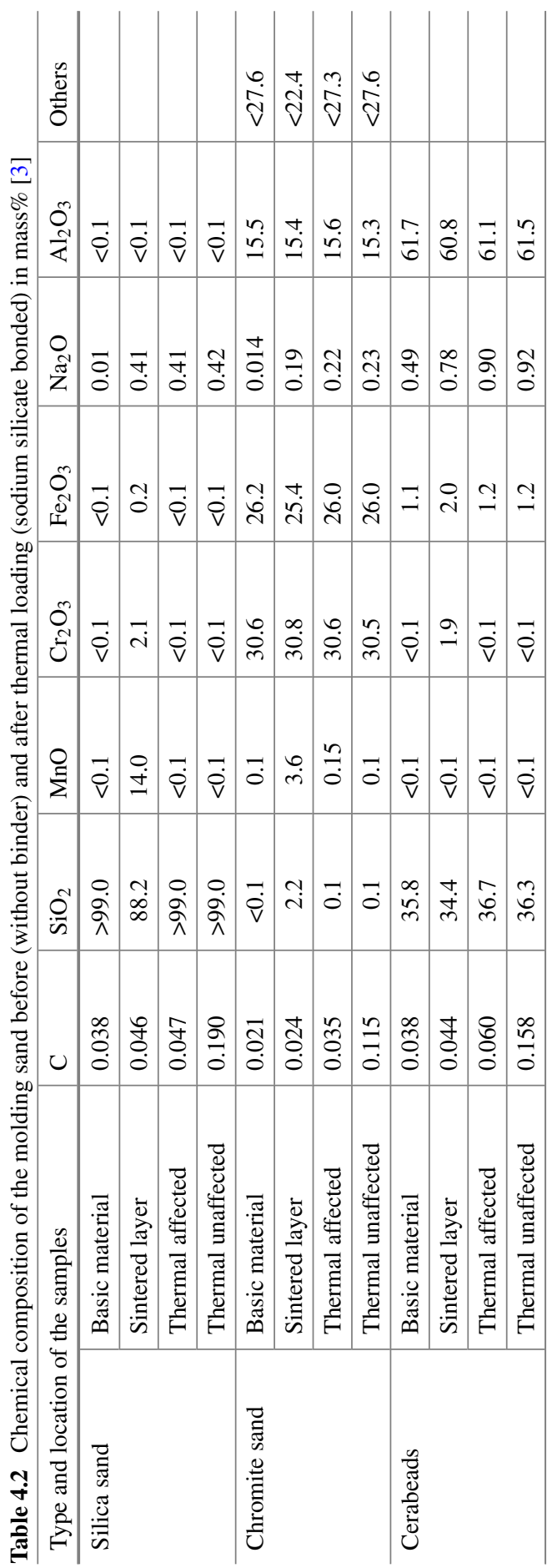


According to Dubberstein and Heller [6], the dynamic viscosity can be reduced by increasing the phosphorus content in the melt [6]. Therefore, the phosphorus contents in the steel melt were increased up to 0.2 mass\% [7].

The effect of the preheating temperature on the infiltration of 10 ppi ceramic filter with a cast steel $\mathrm{X} 3 \mathrm{CrMnNi} 16-7-6$ is shown in Fig. 4.3. Due to the fact, that the melt cools down while flowing through the ceramic, the infiltration quality generally decreases with increasing depth of infiltration. The infiltratable cavity thickness is primarily dependent on the sample position, and thus on the flow length within the filter. A significant influence can only be detected in the middle section of the sample at a preheating temperature of $1400{ }^{\circ} \mathrm{C}$. In the case of the proportion of infiltrated cavities, in addition to the dependence on the sample position, a dependence on the preheating temperature can also be determined, which is best visible in the lower areas. When these lower areas are underheated due to the low temperature of the melt or not efficient preheating of the ceramic filter, the melt solidifies faster, and the infiltration of the small cavities was impossible. As a result, the tests were performed with an additional cavity in the lower part of the mold, yielding a more uniform infiltration quality $[3,7]$.

The effect of the phosphorus content in the melt on the infiltration quality is shown in Fig. 4.4. By adding phosphorus, it is possible to infiltrate the 10 ppi filters preheated to $1000{ }^{\circ} \mathrm{C}$ nearly independent of the sample area. The best results concerning to the cavity thickness as well as the fraction of the infiltrated cavities were achieved by a phosphorus content of 0.2 mass $\%[3,7]$.

To conclude, the infiltration quality depends primarily on the phosphorus content of the melt and thus on the viscosity and the melt flow through the filter package.

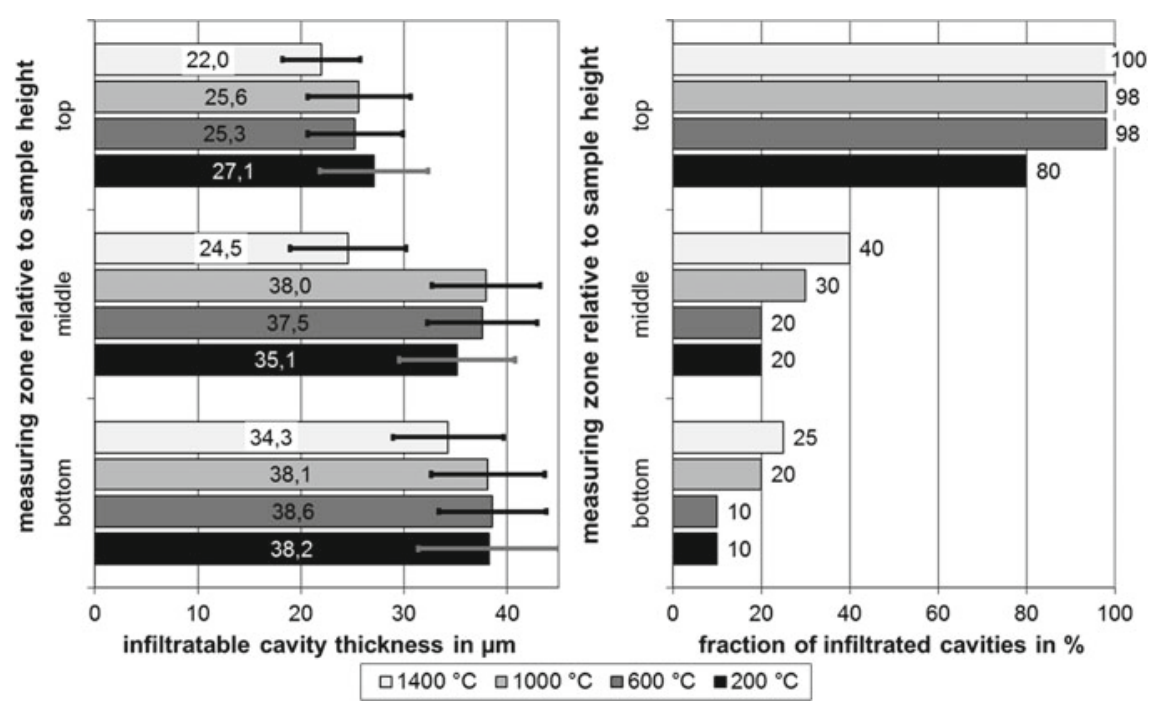

Fig. 4.3 Effect of the preheating temperature on the infiltration quality (cast steel $\mathrm{X} 3 \mathrm{CrMnNi}$ 16-7-6 and 10 ppi filter). Adapted from Weider [3] 


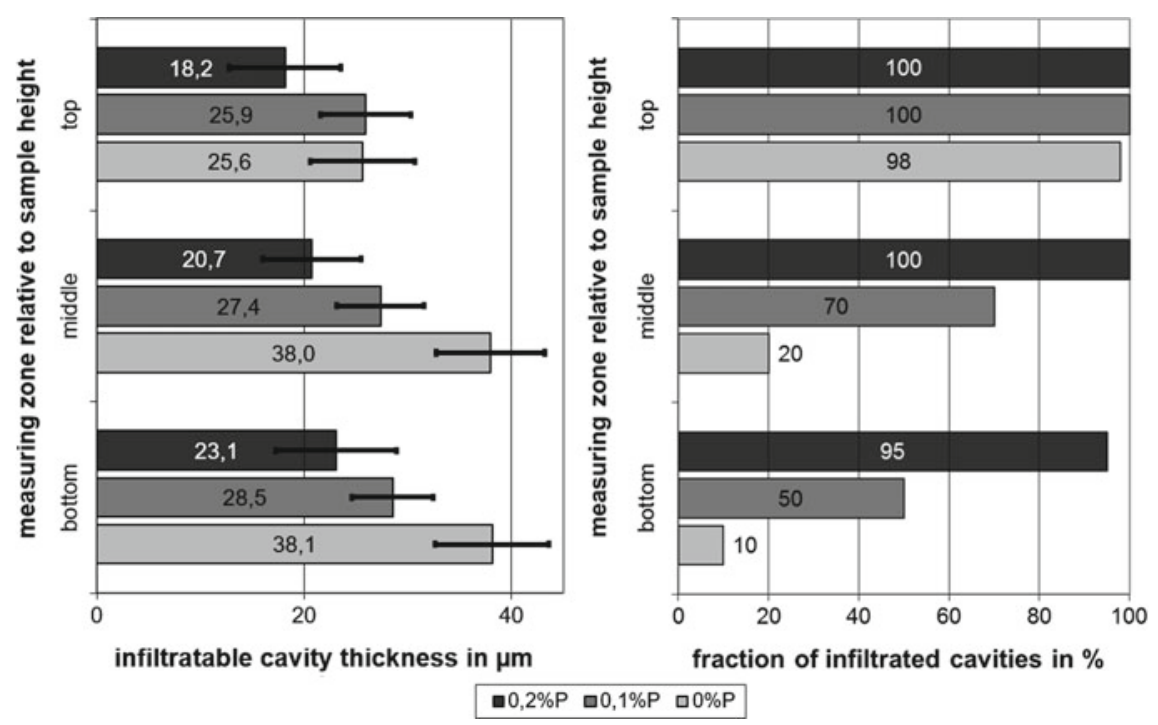

Fig. 4.4 Effect of phosphorus on the infiltration quality (cast steel $\mathrm{X} 3 \mathrm{CrMnNi}$ 16-7-6 and 10 ppi filter). Adapted from Weider [3]

The influence of the preheating temperature of the ceramic filter before casting is less important in comparison to the location of the filter. In order to ensure a better infiltration quality, it is advisable to have an additional cavity under the filter package to preheat the ceramics by the additional melt flowing through the filters $[3,7]$.

\subsection{Wear Properties of $\mathrm{ZrO}_{2}$-Based Metal-Matrix-Composites}

Metals can be reinforced with hard particles to increase the wear resistance of casings. For example, wear resistant parts are often made of white cast iron with a high content of carbide building elements, hard particles precipitating during solidification and heat treatment. If the hardness and wear resistance of the composites increases, the toughness often decreases. Therefore metastable austenitic-martensitic steels were chosen as matrix material, which demonstrates a TRIP-effect and transforms into $\alpha^{\prime}$-martensite by applying a load. As a consequence, the core of the castings is comparatively tough compared to the transformed wear area $[8,9]$.

To ensure good bonding of the steel to the ceramic, it is advisable to influence the thermophysical properties of the liquid melt. In addition to the contact angle and viscosity, the surface tension of the liquid melt can be reduced and the ability to infiltrate small pores in the porous ceramic structures can be increased. The flowability of $\mathrm{CrMnNi}$ steels can be increased by up to $0.18 \%$ of phosphorus content, so that 
porous structures are infiltrated without any negative influence on the mechanical properties of the steel [7]. Furthermore, the contact angle between ceramic and melt can be reduced by adding titanium on the ceramic surface [10]. Dubberstein et al. reported in [11] about the influence of sulfur on the contact angle. Accordingly, the contact angle decreases from $102^{\circ}$ at a sulfur content of $137 \mathrm{ppm}$ to $92^{\circ}$ at a sulfur content of $696 \mathrm{ppm}$.

\subsubsection{Three-Body Abrasive Test}

The characterization of the abrasive wear properties was carried out at a block/ringtesting station. The block/ring-testing station allows a variety of sample sizes, abrasive materials and metal pairings at different speeds and contact pressures. The results of the tribological test are a system parameter [12]. The most important advantage to other wear testing techniques is the variable sample size, so that the tests are also possible with MMCs with infiltrated hard particles in the range from $5 \mathrm{~mm}$ to $10 \mathrm{~mm}$. The castings, needed for producing the wear samples, were manufactured as described in chapter 4.2. A 3.4 mass $\%$ magnesia partially stabilized zirconia foam structure with a porosity of 30 ppi was infiltrated. As matrix material metastable austenitic-martensitic $\mathrm{X} 3 \mathrm{CrMnNi}$ 16-7-3 and 16-7-6 steels were chosen. The steel is poured into the infiltration mold at a casting temperature of $1600{ }^{\circ} \mathrm{C}$. After solidification and cooling, the casting is machined and samples are taken out from the center of the infiltration area to investigate the wear properties. The samples had the dimensions $65 \times 25 \times 20 \mathrm{~mm}^{3}$ with a $5 \mathrm{~mm} 45^{\circ}$ bevel. A schematic illustration of the block/ring-testing station can be seen in Fig. 4.5 [9].

Abrasive particles can be dispersed in front of the sample for three-body abrasion. In these tests silica sand with a grain size of $0.1-0.5 \mathrm{~mm}$ flow out constantly in front of the chamfered edge to ensure new sand grains for each rotation. The sample was pressed onto the NiHard 4 ring with a load of $0.5 \mathrm{MPa}$, whereby the ring with a
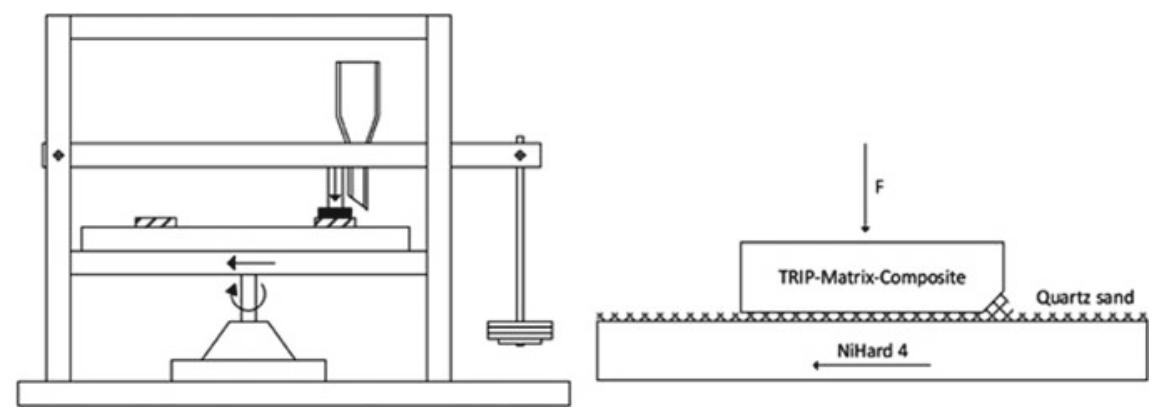

Fig. 4.5 Schematic illustration of the block/ring wear test [8] 




Fig. 4.6 Cumulative decrease in mass versus distance

circumference of $1.153 \mathrm{~m}$ was rotated with $26 \mathrm{~min}^{-1}$. After 1000 rounds, the mass of the sample was measured and the wear test continued for at least $15 \mathrm{~km}[8,9]$.

Figure 4.6 shows the decrease in mass of the wear samples over the distance on the block/ring-testing station. After an uneven loss of mass during the begin of the measurement, it stabilizes with increasing mileage. At the first $10 \mathrm{~km}$, the 16-7-3$\mathrm{ZrO}_{2}$ sample demonstrates higher wear in comparison to the other samples. After that, it has decreased strongly and stabilized at $22 \mathrm{~km}$. The pure TRIP steel has a significantly lower wear rate compared to construction steel. In order to evaluate the results better, the increase in wear is related to the distance. However, only the areas after the wear has evened out are considered. The results are shown in Table 4.3. The designations S800, S1000, P1800 and P2000 given therein describe the respective sulfur and phosphorus content in ppm.

Due to the lower $\mathrm{M}_{\mathrm{s}}$-temperature of the steel 16-7-3 compared to the steel 16-7-6, even smaller local stresses lead to martensitic transformation and thus to better wear behavior. The wear also increases with a fineness of the foam ceramics and with the sulfur as well as with the phosphorus content of the samples. The better infiltration tendency of sulfur-alloyed steels cannot compensate for the tendency of increasing wear known from the literature [9]. The finer foam ceramics have thin struts as well as a high microporosity due to the manufacturing process. This means that the ceramics have little resistance to abrasive wear, which is associated with breaking out of the metal matrix. 
Table 4.3 Average wear in mass loss per distance and its standard deviation. Adapted from Acker [9]

\begin{tabular}{l|l|l}
\hline Material & Mass loss per distance $(\mathrm{mg} / \mathrm{km})$ & Standard deviation $(\mathrm{mg} / \mathrm{km})$ \\
\hline $16-7-3$ & 116 & 31 \\
\hline $16-7-6$ & 134 & 55 \\
\hline S235JR & 241 & 64 \\
\hline $16-7-3 \mathrm{~S} 800+30$ ppi $\mathrm{ZrO}_{2}$ & 103 & 35 \\
\hline $16-7-3 \mathrm{P} 1800+60 \mathrm{ppi} \mathrm{ZrO}_{2}$ & 207 & 72 \\
\hline $16-7-3 \mathrm{P} 2000+60{\mathrm{ppi} \mathrm{ZrO}_{2}}$ & 263 & 114 \\
\hline $16-7-6 \mathrm{~S} 1000$ & 318 & 99 \\
\hline $16-7-6+20 \mathrm{ppi} \mathrm{ZrO}_{2}$ & 139 & 42 \\
\hline $16-7-6+30 \mathrm{ppi} \mathrm{ZrO}_{2}$ & 223 & 78 \\
\hline
\end{tabular}

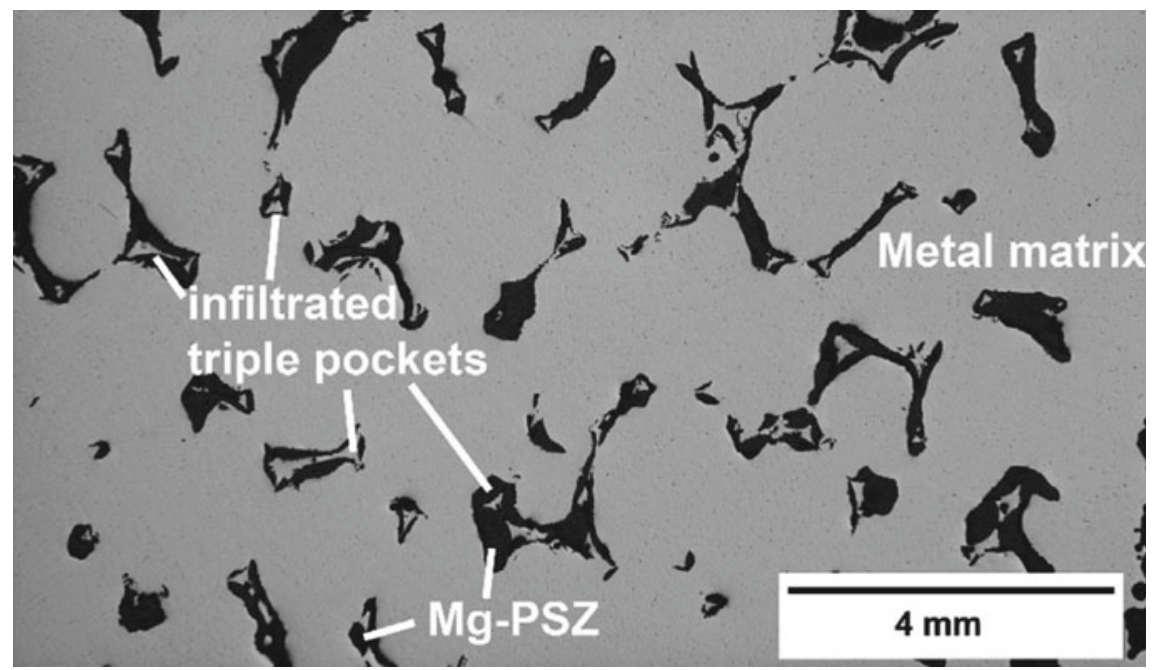

Fig. 4.7 Optical micrograph of a MMC containing cast steel X3CrMnNi 16-7-3 steel, alloyed with $800 \mathrm{ppm}$ sulfur, and $30 \mathrm{ppi} \mathrm{Mg-PSZ-foam} \mathrm{ceramic} \mathrm{[8]}$

\subsubsection{Microscopy of the MMC}

After casting, the samples were cut out of the middle part of the infiltration area at a distance of approx. $20 \mathrm{~mm}$ from the wall. Besides an optical microscope evaluation (Olympus BX51M), a scanning electron microscope investigation was carried out (ZEISS LEO 1530) with $20 \mathrm{kV}$ in the backscattered contrast mode.

Figure 4.7 shows a micrograph of a 30 ppi Mg-PSZ foam and X3CrMnNi 16-7-3 alloyed with 800 ppi sulfur. Macroscopically no shrinkage cavities are visible. From a sulfur content of $500 \mathrm{ppm}$, the surface of the melt is covered with sulfur and thus 


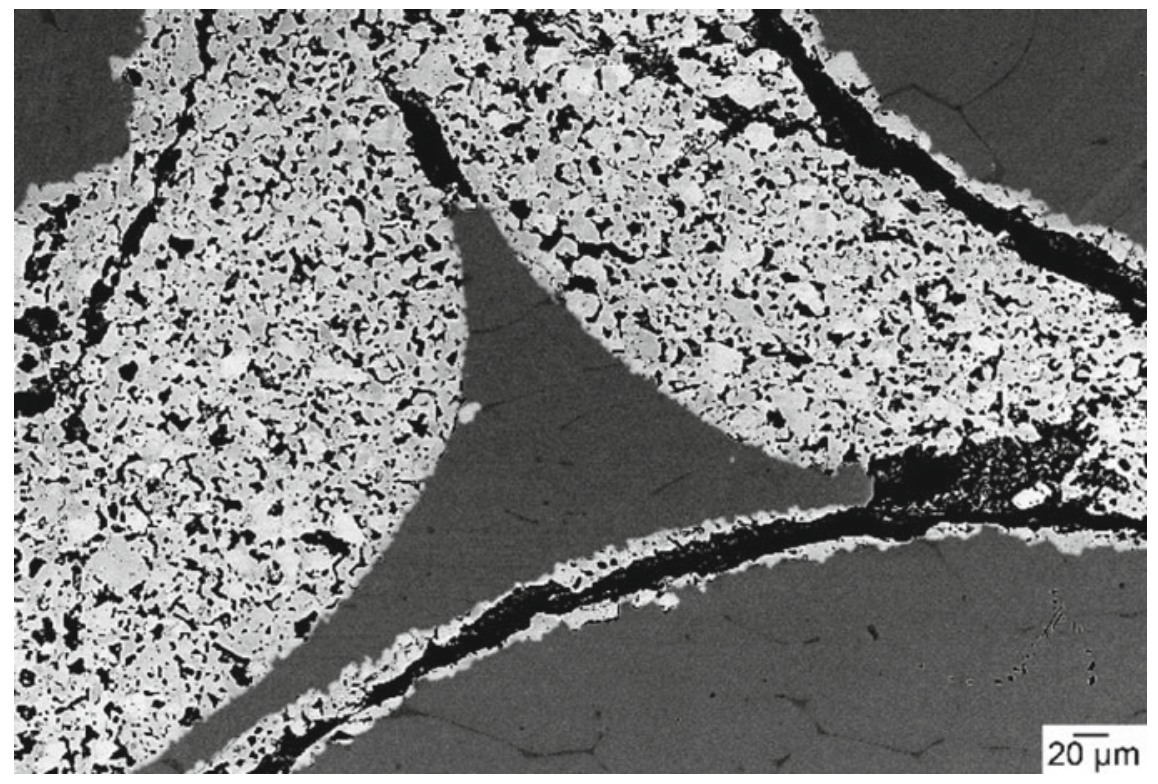

Fig. 4.8 SEM image of a 30 ppi Mg-PSZ foam infiltrated by cast X3CrMnNi 16-7-3 steel with cracks in the ceramic structure [9]

the surface tension of the melt is determined, so that the triple pockets could be filled [13].

In a closer SEM investigation, as displayed in Fig. 4.8, the good quality of the interface bonding is visible on a microscopic level. Due to the porosity-related low strength of the ceramic, the cracks do not run along with the interface, but within the ceramic. The different coefficients of expansion of steel and ceramic and the good interface bonding are leading to a stress gradient in the ceramic and the interface, which ultimately leads to cracks in the porous ceramic foams [14]. The tendency to crack formation is promoted by the infiltration of foam structures, since ceramic struts of different widths allow the melt to cool locally at different rates, which is associated with an increase in stress differences.

\subsection{Infiltration of Loose Ceramic Particles with Steel and Their Wear Behavior}

The MMC containing TRIP-steel and foam ceramics described in the previous chapter have no significant influence on the wear resistance. The expected phase transformation in the Mg-PSZ ceramic foam cannot be observed, because the force transmission of the deforming steel matrix is not sufficient. As a consequence the effect of closing micro cracks due to the transformation of the ceramic does not 
occur in the present case [3]. In addition to the infiltration of the ceramic foams, the infiltration of loose ceramic particles has proven to be a practical way of producing wear-loaded cast parts with local ceramic reinforcement. Basic tests were carried out with the mold shown in Fig. 4.1. Special attention was paid to the wear resistance of the MMC and the interface between steel and ceramic. In order to transfer the knowledge gained to practice, a new possibility was developed to produce locally reinforced MMC in gravity casting. For this purpose, the lower density of the ceramics was exploited by rinsing the hard particles in a targeted manner.

\subsubsection{Static Infiltration of Loose Ceramic Particles}

Similar to the infiltration of ceramic foams, loose ceramic bulks were infiltrated. As matrix material, a high alloyed metastable austenitic-martensitic $\mathrm{X} 3 \mathrm{CrMnNi}$ 16-7-3 was chosen. The composition is shown in Table 4.4. Due to its low $M_{\mathrm{s}}$-Temperature of $61{ }^{\circ} \mathrm{C}$, the chosen steel needs only low triggering stresses to transform from austenite to martensite [15]. As reference material, NiHard 4 in its cast and heat treated state was investigated. The composition is also displayed in Table 4.4.

As reinforcing material three hard particles, displayed in Table 4.5, were infiltrated. The aluminum oxide spheres have a particle size of $6.4 \mathrm{~mm}$ (Mühlmeier Mahltechnik, Germany). The white fused mullite (WFM) and the fused zirconia mullite (ZrM) (Imerys Fused Minerals, Germany) have a particle size between 4 and $12 \mathrm{~mm}$. The WFM shows a uniform $\mathrm{Al}_{2} \mathrm{O}_{3}$-rich mullite structure with approx. $80 \%$ $\mathrm{Al}_{2} \mathrm{O}_{3}$ and $20 \% \mathrm{SiO}_{2}$ containing only minor $\mathrm{SiO}_{2}$-rich areas. The $\mathrm{ZrM}$ consists of a mullite structure with incorporated $\mathrm{ZrO}_{2}$-grains. All three ceramics exhibit lower thermal expansion coefficients between 5.0 and $6.410^{-6} \mathrm{~K}^{-1}$ compared to high alloyed stainless steels with a range of $16-18 \times 10^{-6} \mathrm{~K}^{-1}[16]$.

According to their higher insulation capacity according to silica sand, CeraBeads 650 (Hüttenes-Albertus, Germany) were used as molding sand [4]. Sodium silicate binder is well known to minimalize the chemical reactions between the steel and the

Table 4.4 Chemical composition of the used TRIP-steels and the reference material. Adapted from Acker [9]

\begin{tabular}{|c|c|c|c|c|c|c|c|c|c|}
\hline \multirow[t]{2}{*}{ Alloy } & $\mathrm{C}$ & $\mathrm{Si}$ & $\mathrm{Cr}$ & $\mathrm{Mn}$ & $\mathrm{Ni}$ & Mo & $\mathrm{P}$ & $\mathrm{S}$ & $\mathrm{Fe}$ \\
\hline & \multicolumn{9}{|c|}{$(\operatorname{mass} \%)$} \\
\hline $\begin{array}{l}\text { X3CrMnNi 16-7-3 } \\
\text { ZrM }\end{array}$ & 0.045 & 0.84 & 15.9 & 6.8 & 3.4 & 0.042 & $<0.003$ & 0.009 & Bal. \\
\hline $\begin{array}{l}\text { X3CrMnNi 16-7-3 } \\
\text { WFM }\end{array}$ & 0.045 & 0.85 & 15.7 & 6.7 & 3.4 & 0.034 & $<0.003$ & 0.006 & Bal. \\
\hline $\begin{array}{l}\mathrm{X} 3 \mathrm{CrMnNi} \text { 16-7-3 } \\
\mathrm{Al}_{2} \mathrm{O}_{3}\end{array}$ & 0.054 & 0.88 & 15.7 & 6.7 & 3.3 & 0.037 & $<0.003$ & 0.007 & Bal. \\
\hline $\begin{array}{l}\text { NiHard } 4 \text { heat } \\
\text { treated }\end{array}$ & 3.26 & 1.37 & 10.2 & 0.6 & 5.7 & 0.180 & 0.015 & 0.07 & Bal. \\
\hline
\end{tabular}




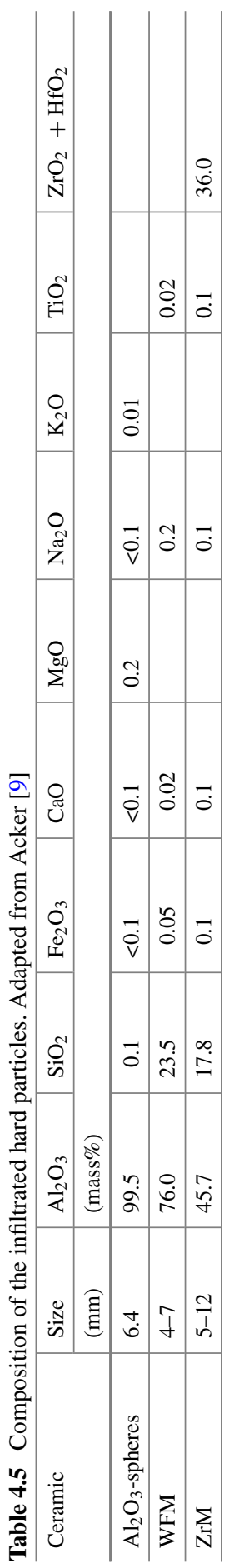


molding sand and is therefore used. The steel was melt in a $30 \mathrm{~kg}$ open induction furnace. Directly before casting the preheated ceramics up to $1400{ }^{\circ} \mathrm{C}$ were filled into the mold. In order to prevent floating of the ceramics a 10 ppi casting filter (Drache, Germany) was placed on the ceramic heap and secured against floating with glass rods (Fig. 4.1). To ensure a minimum of heat loss, the melt was poured with a temperature of $1600{ }^{\circ} \mathrm{C}$ directly from the induction furnace into the mold.

After casting and cooling microscope investigation and three-body-abrasive tests were carried out.

\subsubsection{Microscopy}

All samples were completely infiltrated, depicted in Fig. 4.9. There was no macroscopic porosity and because of the directional solidification from the lower area to the upper one, there were no local cold runs visible.

At higher magnification, shown in Fig. 4.10, gaps of 10-20 $\mu \mathrm{m}$ can be seen for the $\mathrm{Al}_{2} \mathrm{O}_{3}$-steel composite. In the shown section no bonding between the steel and the aluminum oxide spheres is visible. The gaps result in breaking out of the spheres during machining. With the help of the SEM examination, it was possible to prove that oxides from the corundum side are on the steel surface and chromium, iron and manganese are located on the ceramic side. It can be therefore assumed that wetting has taken place and that the bond has broken as a result of solidification and cooling. The two materials move away from each other as a result of shrinkage. The cracks are caused by the stresses generated by the different thermal expansion coefficients.

Both mullites show a better interface connection. Slag phases were formed in the mullites. The white fused mullite formed a spessartite phase with a composition of $34 \% \mathrm{MnO}, 40 \% \mathrm{SiO}_{2}$ and $22 \% \mathrm{Al}_{2} \mathrm{O}_{3}$ and a resulting melting phase of $1195{ }^{\circ} \mathrm{C}$. In zirconium mullite, the spessartite-like phase formed had a composition of $26 \%$ $\mathrm{Al}_{2} \mathrm{O}_{3}, 37 \% \mathrm{SiO}_{2}, 30 \% \mathrm{MnO}$ and $2 \% \mathrm{NaO}$ with a melting point below $1300{ }^{\circ} \mathrm{C}[17$, 18]. The comparatively low melting point of the slags buffers the stresses arising during cooling down to their solidification temperature.


Fig. 4.9 Sectional views of the $\mathrm{MMC}$, a $\mathrm{Al}_{2} \mathrm{O}_{3}$-spheres, $\mathbf{b} \mathrm{WFM}, \mathbf{c} \mathrm{ZrM}$ 


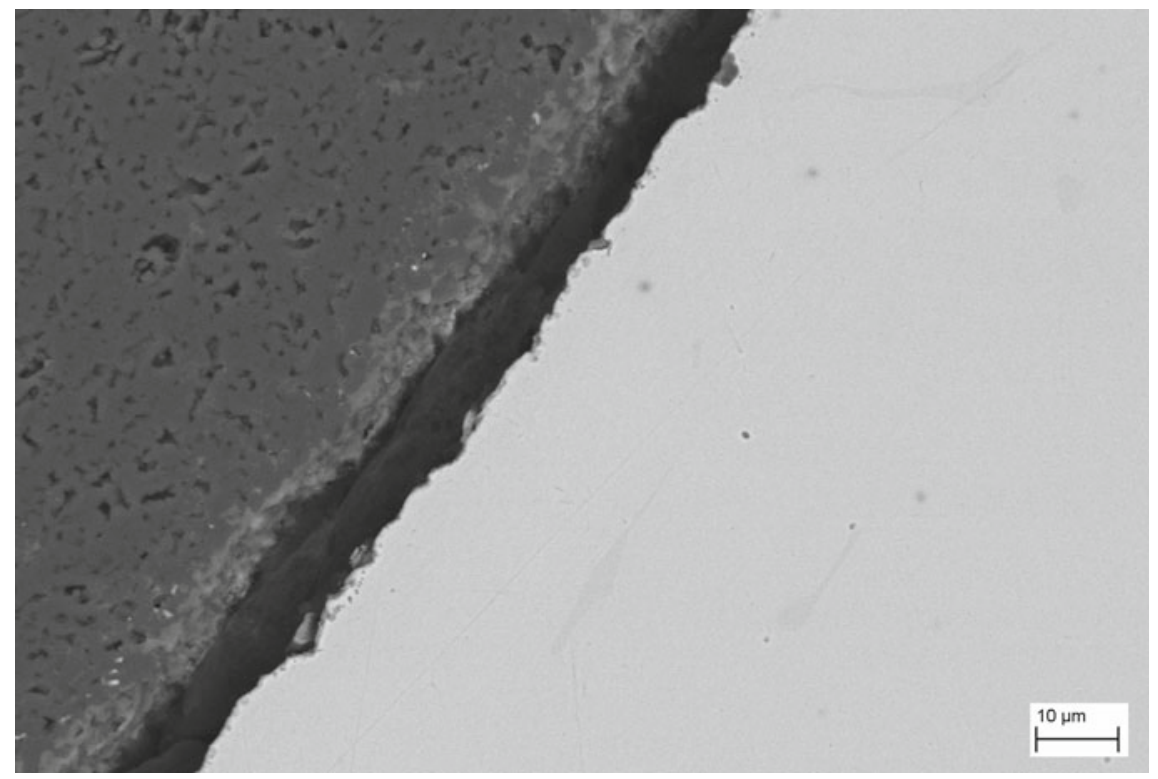

Fig. 4.10 SEM image of a MMC consisting of $9.6 \mathrm{~mm} \mathrm{Al}_{2} \mathrm{O}_{3}$ spheres and $\mathrm{X} 3 \mathrm{CrMnNi} 16-7-3$ with the cooling crack between both materials

The irregular grain shapes creates a frictional connection between the matrix and the reinforcing phases. In addition, there was a different shrinkage in different directions of the ceramics because of the irregular particle shapes. The molten steel could image even small gussets on the ceramic side. Therefore, cracks in the boundary layer caused by cooling were unavoidable.

\subsubsection{Wear Behavior}

The wear behavior of the samples was investigated at a block/ring-station, as described above. The results are shown in Fig. 4.11. When comparing the wear rate as a decrease in mass per distance, the zirconia mullite based MMC demonstrates a wear reduction down to $93 \mathrm{mg} \mathrm{km}^{-1}$ and white fused mullite based MMC of $64 \mathrm{mg} \mathrm{km}^{-1}$. Due to the breaking out of the corundum spheres, the wear value of the $\mathrm{Al}_{2} \mathrm{O}_{3}$-steel composite was not evaluated.

Generally, the mullite-based composites show better wear rates compared to NiHard4 and the cast X3CrMnNi 16-7-3 steel. The amount of $\alpha$ '-martensite in the investigated TRIP-steel is increasing up to $97 \%$ at the loaded surface [8]. The effect of the near-surface martensitic transformation and the associated increase in hardness is intensified by the addition of ceramics, which are form-fittingly embedded in the matrix. 


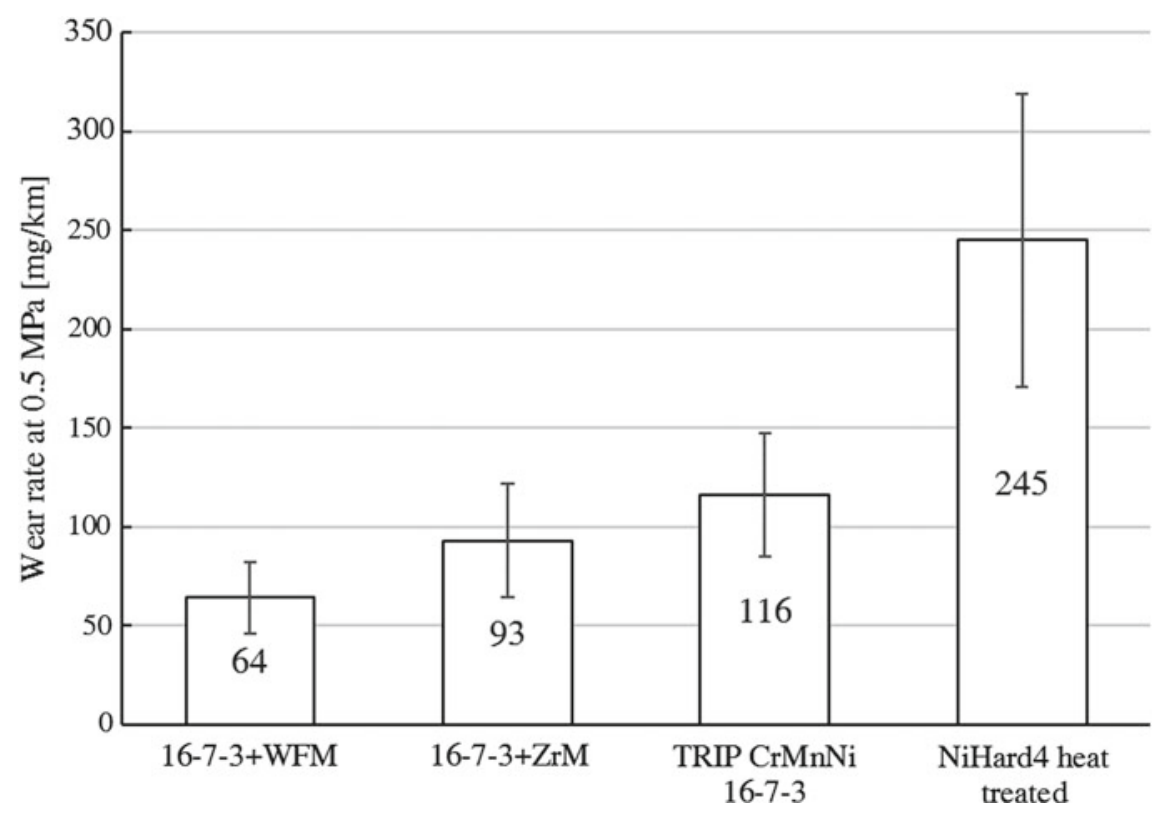

Fig. 4.11 Wear rate as a decrease in mass per distance

\subsubsection{Interfacial Optimization by Coating with Titanium Oxide}

Titanium is known as an alloying element because it is soluble in steels and also as an oxide in $\mathrm{Al}_{2} \mathrm{O}_{3}$. The absorption of titanium into the ceramic surface creates a layer that can serve as a bonding layer between metal and ceramic [17]. Especially on aluminum oxide, titanium melts can lead to an improvement of the interfacial bonding through the formation of titanium oxides and $(\mathrm{Ti}, \mathrm{Al})_{2} \mathrm{O}_{3}$ phases as well as intermetallic phases [18]. With this background, the interest was to improve the interface between steel and ceramics by the formation of aluminum titanate with the aim of crack reduction. Aluminum titanate is a high temperature phase which decomposes without the presence of stabilizers such as $\mathrm{Fe}_{2} \mathrm{O}_{3}$ or $\mathrm{Si}_{2} \mathrm{O}_{3}$ into rutile and $\alpha-\mathrm{Al}_{2} \mathrm{O}_{3}$ at a temperature below $1280{ }^{\circ} \mathrm{C}[19]$.

First, the corundum spheres and mullite particles were produced by pelletizing in aqueous suspension, consisting of $30 \% \mathrm{TiO}_{2}$ powder and water, by dipping, drying and subsequent sintering. After mixing the spheres for $180 \mathrm{~s}$, they were separated from the slurry using a sieve and then dried in a drying furnace for $24 \mathrm{~h}$ at $60{ }^{\circ} \mathrm{C}$. The subsequent firing process was carried out at $1050^{\circ} \mathrm{C}$, to prevent the formation of aluminum titanate, as it can form at temperatures of $1100{ }^{\circ} \mathrm{C}$ and above [20].

After steel infiltration, the titanium oxide coated materials had a peripheral zone, which can be seen in Fig. 4.12. During the infiltration process, a reaction took place between the titanium oxide and the aluminum oxide. The interface layer between steel and ceramic had a thickness of about $10 \mu \mathrm{m}$ and yielded a better connection. The 




Fig. 4.12 SEM image of the interface between coated corundum spheres and X3CrMnNi 16-7-3

Table 4.6 Composition of the interface

\begin{tabular}{l|l|l|l|l}
\hline & $\mathrm{Al}_{2} \mathrm{O}_{3}$ & $\mathrm{MnO}$ & $\mathrm{TiO}_{2}$ & $\mathrm{Cr}_{2} \mathrm{O}_{3}$ \\
\hline & $(\mathrm{mass} \%)$ & 41 & 2 & 7 \\
\hline Boundary layer & 50 & 38 & 6 & 4 \\
\hline Incorporated spinel & 52 & \multicolumn{4}{|l}{} \\
\hline
\end{tabular}

EDX analysis of the interface, shown in Table 4.6, demonstrates, that a manganeserich compound was formed with titanium oxides and aluminum oxide, which had a liquid phase fraction of up to $1100{ }^{\circ} \mathrm{C}$ and can therefore reduce stresses arising during cooling. The macroscopically visible discolorations consist of $\mathrm{Al}_{2} \mathrm{O}_{3}$ grains with incorporated spinel compound, which had a composition similar to the boundary layer. It can be assumed that the temporarily formed aluminum titanate has been transformed into manganese aluminate and manganese titanate by the presence of manganese.

\subsubsection{Dynamic Infiltration of Loose Ceramic Particles}

With the static infiltration method, it is difficult to produce industrial castings with a local ceramic reinforcement. In addition to static infiltration, where the ceramics 
are infiltrated as bulk, the ceramics can also be infiltrated dynamically. This means that the ceramics are transported flow-induced through the melt to their destination. The large difference in density between steel and ceramics can consciously be used to rinse ceramics in the upper part of the casting.

Initially, a casting mold was developed, which makes only infiltration of ceramic particles possible, as it turned out that ceramic foams have no positive effect on the wear resistance. The gating system was deliberately designed generously, as the ceramics remove a large amount of heat from the melt despite preheating and this deficit has to be compensated by a larger melt mass.

The aim of the developed infiltration mold is to produce samples for the block/ringtesting station with a local ceramic reinforcement in the wear area, according to Fig. 4.13, with minimal resource expenditure. Between the wear sample and the spherical feeder is the flow zone in which various possibilities can be tested to stop the further buoyancy of the ceramics and to ensure a glistening distribution of these. A $5 \mathrm{~mm}$ thick ceramic filter has proven its worth as insert for the flow zone. A cell filter with a mesh width of $2 \mathrm{~mm}$ is used, as foam filters of this thickness possess not sufficient strength. The falling casting system was chosen, so that the preheated ceramics, which were filled in the sprue directly before casting, were carried along by the turbulences arising during the casting process. As can be seen in Fig. 4.14,



Fig. 4.13 CAD model of the infiltration casting with the wear sample below the spherical feeder 


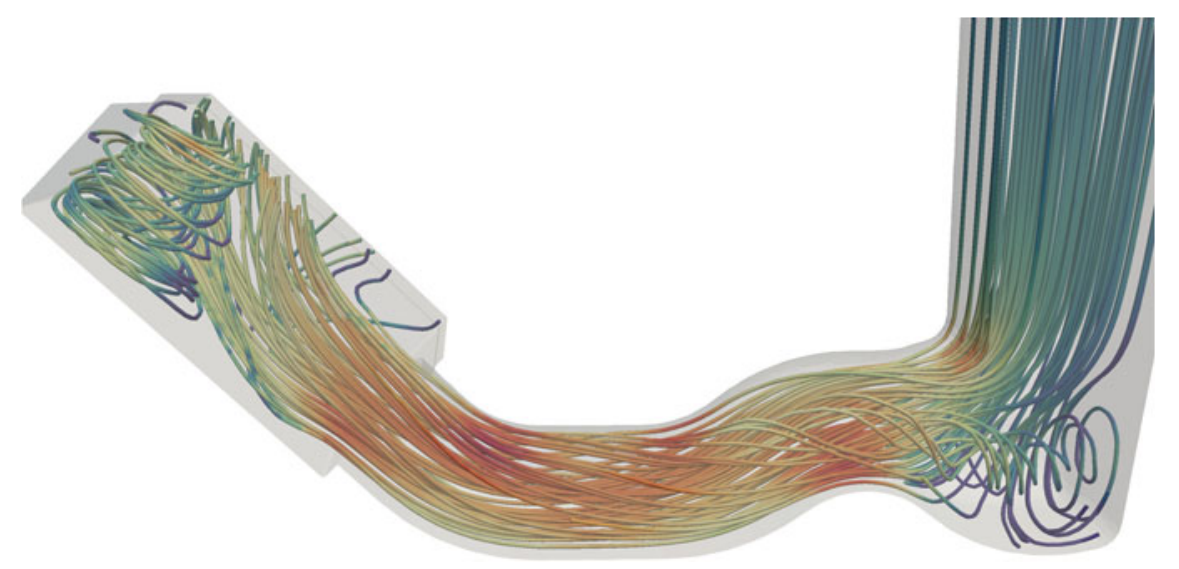

Fig. 4.14 Simulated static flow conditions in the lower area of the mold at the end of the casting process

Table 4.7 Chemical composition of the casted steels

\begin{tabular}{l|l|l|l|l|l|l|l}
\hline \multirow{2}{*}{ Alloy } & $\mathrm{C}$ & $\mathrm{Si}$ & $\mathrm{Cr}$ & $\mathrm{Mn}$ & $\mathrm{Ni}$ & $\mathrm{Mo}$ & $\mathrm{Fe}$ \\
\cline { 2 - 9 } & \multicolumn{7}{l|}{ (mass\%) } \\
\hline X3CrMnNi 16-7-3 & 0.04 & 1.08 & 16.91 & 6.4 & 2.93 & 0.02 & Bal. \\
\hline Mn-Hard & 1.47 & 0.643 & 0.34 & 13.58 & 0.11 & 0.004 & Bal. \\
\hline
\end{tabular}

the pressurized casting system leads to high flow velocity in the gate, so that as few ceramic particles as possible accumulate on the molding material wall. Due to the $45^{\circ}$ inclination of the test specimen, the ceramics were rinsed specifically against the filter. After cooling down and solidification, the casting was machined by removing the gating and the feeder system with the flow zone, so that the resulting wear sample can be used directly at the block/ring-testing station.

A TRIP steel X3CrMnNi 16-7-3 and a Hadfield steel (called Mn-Hard) were selected for the tests. The compositions are shown in Table 4.7. Melting took place in a $50 \mathrm{~kg}$ induction furnace. After deoxidizing with 0.05 mass $\%$ aluminum, the melt was poured into the mold at a pouring temperature of $1600{ }^{\circ} \mathrm{C}$. Before casting, the zircon corundum particles were heated up to $1400{ }^{\circ} \mathrm{C}$ in a laboratory furnace. Above $1400{ }^{\circ} \mathrm{C}$, a sintering process begins so that the particles cannot be preheated at higher temperatures. An infiltration of not preheated ceramics could not be carried out successfully, because a solidified steel shell immediately formed around the ceramics, which prevented the ceramics from flowing away as well as an infiltration of the particles. The composition of the particles (Imerys Fused Minerals, Germany) with a size between 1230 and $1765 \mu \mathrm{m}$ is shown in Table 4.8. 
Table 4.8 Composition of the infiltrated zircon corundum particles

\begin{tabular}{l|l|l|l|l}
\hline $\mathrm{Al}_{2} \mathrm{O}_{3}$ & $\mathrm{ZrO}_{2}+\mathrm{HfO}_{2}$ & $\mathrm{TiO}_{2}$ & $\mathrm{Fe}_{2} \mathrm{O}_{3}$ & $\mathrm{Si}-, \mathrm{Mg}-, \mathrm{Ca}-, \mathrm{Na}-, \mathrm{K}-O x i d e$ \\
\hline \multicolumn{5}{|l}{ (mass\%) } \\
\hline 55.0 & 41.0 & 3.0 & 0.1 & 0.9 \\
\hline
\end{tabular}


Fig. 4.15 Optical microscope images of infiltrated zirconia corundum with $\mathrm{X} 3 \mathrm{CrMnNi}$ 16-7-3 (a) and Mn-Hard (b)

\subsubsection{Microscopy}

In order to assess the interface connection, microscopic examinations were carried out analogously to the previous chapters. On the one hand, images were taken with an optical microscope and on the other hand, pictures including line scan were performed with SEM. Figure 4.15 shows the bonds between the $\mathrm{TiO}_{2}$ coated zirconia corundum and the two different types of steel. The ceramic has only a low porosity, which is important for good wear behavior. Both steels show a very good bond. By this kind of infiltration, whereby the ceramics are whirled by the melt, the liquid steel has sufficient time to heat the ceramics, so that a very good clinging takes place between steel and ceramics. The dynamical process is leading to an infiltration of small recesses in the ceramics. Due to the non-compact accumulations of the ceramics, local solidification between the ceramics and thus also the tensions in the boundary layer are reduced. It can be assumed that the steel can shrink onto the ceramic and thus the movement of the materials away from each other is prevented.

In order to analyze the composition of the boundary layer, examinations at a SEM with the aid of EDX are suitable. The line scan is useful to make statements about the change in concentration. The right area of Fig. 4.16 shows the steel, which is characterized by the high iron content. In the left area the ceramic is present, which consists of aluminum, zirconium and oxygen. The visible connecting layer has a thickness of approx. $7 \mu \mathrm{m}$. In comparison to the ceramics, the elements $\mathrm{Mn}, \mathrm{Ti}$ and $\mathrm{Zr}$ are enriched in this area. The content of $\mathrm{Al}$ is below that in the ceramic. These facts coincide with the findings in Sect. 4.5.1.3. Complex manganese-rich mixing phases with a fluctuating $\mathrm{Zr}$ and $\mathrm{Al}$ content arise, which lead finally to a chemical bond between steel and ceramics. 

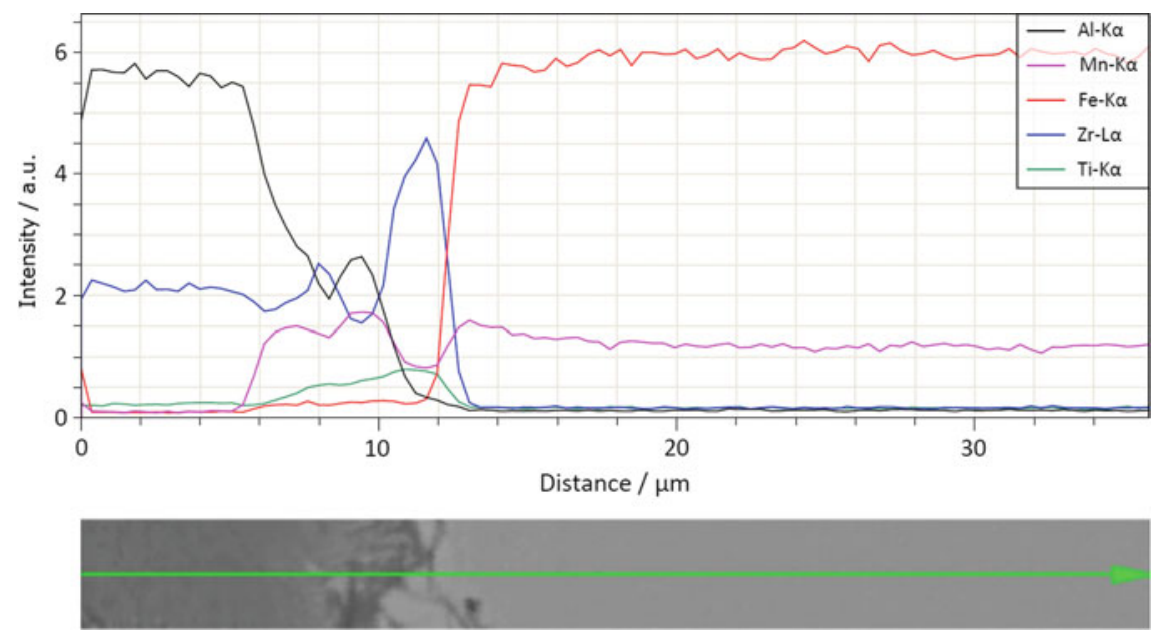

Fig. 4.16 EDX line scan of the boundary layer of $\mathrm{TiO}_{2}$ coated zirconium corundum infiltrated by Mn-Hard steel

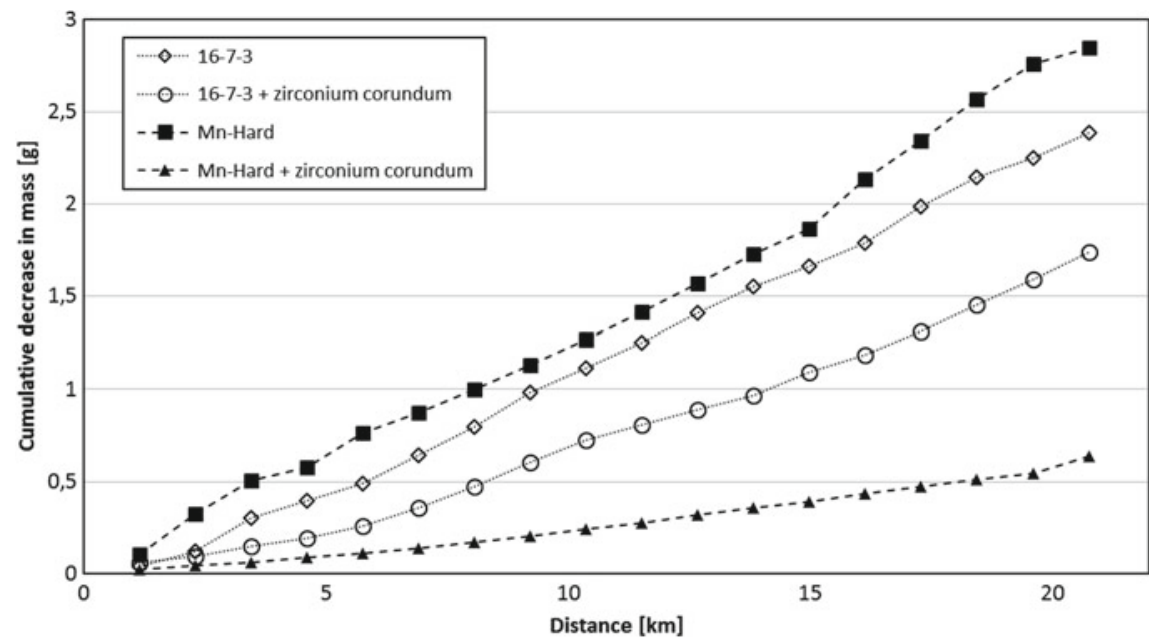

Fig. 4.17 Cumulative decrease in mass versus distance

\subsubsection{Wear Behavior}

The wear behavior of the samples was investigated at the block/ring-station. By optimizing the block/ring-testing station with a steadier supply of quartz sand, a more uniform wear behavior could be observed, which is reflected in straighter curves in Fig. 4.17. The investigations on the block/ring-testing station showed that the $\mathrm{X} 3 \mathrm{CrMnNi}$ 16-7-3 steel behaves similarly in the point of abrasive wear behavior 


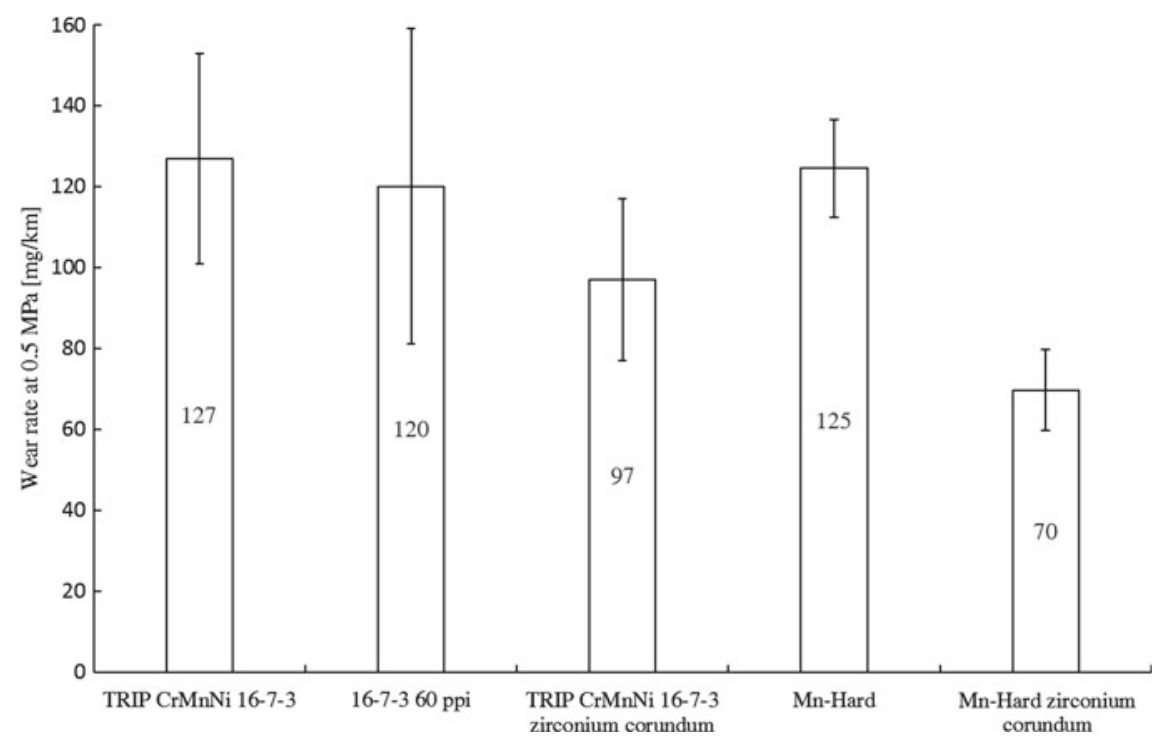

Fig. 4.18 Wear rate as a decrease in mass per distance

compared to the high manganese alloyed steel Mn-Hard. As can be seen in Fig. 4.18, the combination of Mn-Hard and zircon corundum shows the lowest abrasive wear. With a wear value of $70 \mathrm{mg} / \mathrm{km}$, the MMC is significantly more wear resistant than the non-reinforced material. The low standard deviation of the wear value is reflected in the very good bonding and toughness of the zirconium corundum ceramic. These ceramics protrude from the metal matrix and do not break out in brittle layers. Investigations on a 3D microscope showed that the ceramics protrude up to $300 \mu \mathrm{m}$ from the ablated metal matrix. The manufacturer's data show that the fine crystalline structure combined with the high proportion of tetragonal stabilized zirconium oxide produces a very pronounced self-sharpening effect during grinding. In addition to the self-sharpening effect of the ceramic, the good bonding between the steel and the ceramic has proven to be effective.

\subsection{Conclusions}

The manufacturing process of novel metal ceramic composite materials is described. First, basic investigations were carried out on the TRIP steel infiltration of $\mathrm{ZrO}_{2}$ ceramic foams. Different mold materials were investigated and it turned out that Cerabeads have an insulating effect as mold material and that the chemical interactions were lowest. By adding $0.2 \%$ phosphorus, the infiltration quality of $\mathrm{X} 3 \mathrm{CrMnNi}$ 16-7-6 melt can be significantly increased, while the melt temperature in this test arrangement has a lower effect. Furthermore, fine gussets in the ceramic foams can 
be filled by the addition of sulfur. In order to characterize the wear behavior of the new composite materials, tests were carried out on the block/ring-testing station. The investigations revealed that MMCs with infiltrated ceramic foams show no advantage with regard to wear resistance. Rather, the MMCs with ceramic particles have the best wear properties. Particularly noteworthy is the composite of Mn-Hard steel with melt-broken zircon corundum. In addition to the positive effect on the boundary layer by coating the ceramics with $\mathrm{TiO}_{2}$, the interlocking of the irregular particles leads to a reliable connection between ceramics and the steel. Based on these findings, a process was developed to produce a locally reinforced casting. The preheated ceramic particles were filled into the casting mold and then rinsed directly with the molten steel to the desired areas within the mold. The lower density of the ceramics is thus exploited in a targeted manner. This process significantly reduces the tendency to form cracks in the boundary layer between ceramic and steel. Since the ceramics are loose, the steel can shrink onto them. In the future, this process could be used to manufacture wear-resistant components, such as excavator teeth, etc. Figure 4.19 shows a section through the tip of a bucket tooth locally reinforced with ceramic particles, whereby the core of the tooth is free of ceramics and can therefore withstand the impacting stresses. The service life of such components can be extended because of the higher wear resistance, so that costs may be reduced.

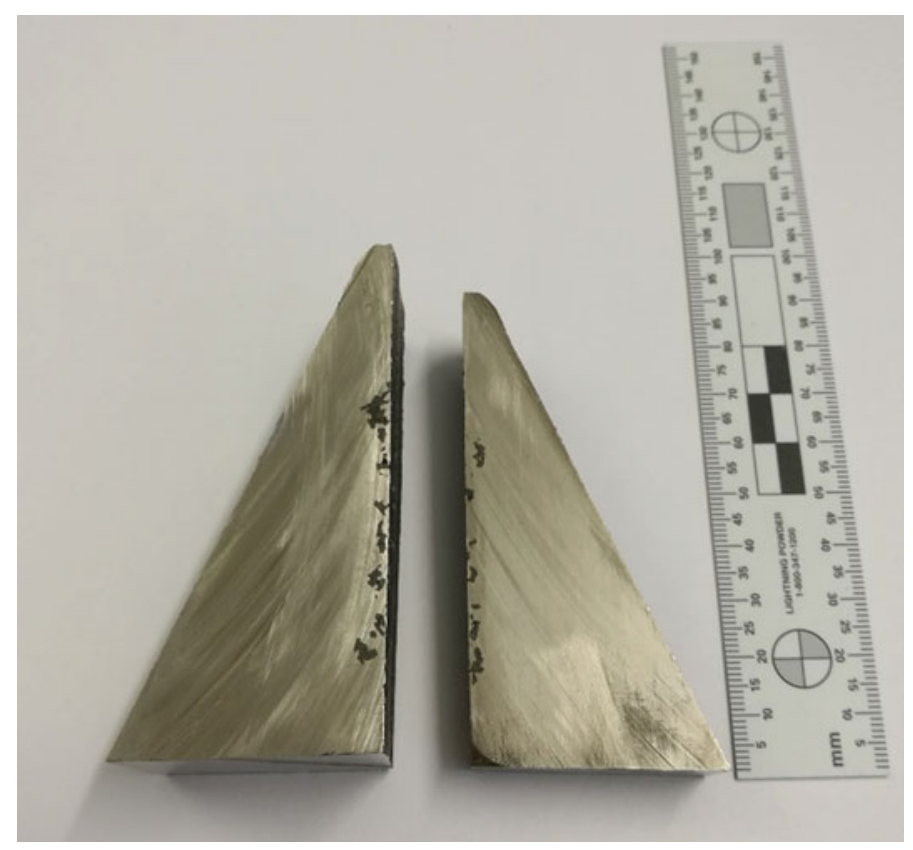

Fig. 4.19 Section through the tip of a bucket tooth locally reinforced with ceramics 
Acknowledgements The authors gratefully acknowledge the financial support for this research by the Deutsche Forschungsgemeinschaft (DFG, German Research Foundation, Project number 54473466 - CRC 799) and Prof. Dr.-Ing. Klaus Eigenfeld, Dr.-Ing. Marco Weider as well as Dr.Ing. Richard Acker for the fundamental research in the field of steel casting infiltration by liquid melt in the subprojects A4, S1 and T4 of the collaborative research center (CRC799) "TRIP-MatrixComposite".

\section{References}

1. A. Jahn, A. Kovalev, A. Wei $\beta$, P.R. Scheller, S. Wolf, L. Krüger, S. Martin, U. Martin, Mechanical properties of high alloyed cast and rolled CrMnNi TRIP steels with varying Ni contents. ESOMAT 2009, 05013 (2009). https://doi.org/10.1051/esomat/200905013

2. M. Weider, H. Polzin, K. Eigenfeld, W. Schärfl, Thermal interactions between casted highalloyed TRIP steel and sodium silicate bonded moulding systems. Refract. World Forum 3, $136(2011)$

3. M. Weider, Doctorate Thesis, TU Bergakademie Freiberg, 2015

4. W. Tilch, M. Martin, Properties and application of alternative moulding sands for the manufacture of light-weight-castings. Gießereiforschung 58, 18 (2006)

5. F.D. Richardson, J.H.E. Jeffes, The thermodynamics of substances of interest in iron and steel making from $0{ }^{\circ} \mathrm{C}$ to $2400{ }^{\circ} \mathrm{C}$ : I-oxides. Iron Steel Inst. 160, 160-261 (1948)

6. T. Dubberstein, H.-P. Heller, Effect of steel viscosity on metallurgical processing, in 6 th International Congress on the Science and Technology of Steelmaking, China Machine Press 2015

7. M. Weider, K. Eigenfeld, Steel Res. Int. 82(9), 1064-1069 (2011). https://doi.org/10.1002/srin. 201100071

8. R. Acker, S. Martin, K. Meltke, G. Wolf, Steel Res. Int. 87(8), 1111-1117 (2016). https://doi. org/10.1002/srin.201500471

9. R. Acker, Doctorate Thesis, TU Bergakademie Freiberg, 2018

10. K. Lemster, T. Graule, J. Kuebler, Mater. Sci. Eng. A 1-2, 385 (2005)

11. T. Dubberstein, H.-P. Heller, C. Wenzel, C.G. Aneziris, in Proceedings of the 10th International Conference of Molten Slags, Fluxes and Salts (Springer International Publishing, Basel, 2016), pp. 1371

12. A. Rosin, Doctorate Thesis, TU Bergakademie Freiberg, 2014

13. S. Seetharaman (ed.), Fundamentals of Metallurgy (Woodhead Publishing Limited, Cambridge, 2005)

14. V. Grethe, Doctorate Thesis, TU Clausthal, 1994

15. A. Kovalev, A. Jahn, A. Weiß, S. Wolf, P.R. Scheller, Steel Res. Int. 82(9), 1101-1107 (2011). https://doi.org/10.1002/srin.201100065

16. W. Martienssen, H. Warlimont, Handbook of condensed matter and materials data (Springer, Heidelberg New York, 2005)

17. D. Wittig, A. Glauche, C.G. Aneziris, T. Minghetti, C. Schelle, T. Graule, J. Kuebler, Mater. Sci. Eng., A 488, 580-585 (2008). https://doi.org/10.1016/j.msea.2007.11.065

18. L. Espié, B. Drevet, N. Eustathopoulous, Metall. Mater. Trans. A 25, 599-605 (1994). https:// doi.org/10.1007/BF02651601

19. C. Weigelt, C.G. Aneziris, D. Ehinger, R. Eckner, L. Krüger, C. Ullrich, D. Rafaja, J. Compos. Mater. 49(28), 3567-3579 (2015)

20. J. Bossert, C. Ludwig, Materialwiss. Werkstofftech. 28(5), 241-245 (1997) 
Open Access This chapter is licensed under the terms of the Creative Commons Attribution 4.0 International License (http://creativecommons.org/licenses/by/4.0/), which permits use, sharing, adaptation, distribution and reproduction in any medium or format, as long as you give appropriate credit to the original author(s) and the source, provide a link to the Creative Commons license and indicate if changes were made.

The images or other third party material in this chapter are included in the chapter's Creative Commons license, unless indicated otherwise in a credit line to the material. If material is not included in the chapter's Creative Commons license and your intended use is not permitted by statutory regulation or exceeds the permitted use, you will need to obtain permission directly from the copyright holder.

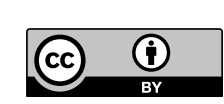

